\title{
BMJ Open Factors associated with the longer-term unmet supportive care needs of stroke survivors in Ethiopia: a multicentre cross-sectional study
}

\author{
Edna Gebremichael Tamrat (D) , ${ }^{1}$ Zenawi Hagos Gufue, ${ }^{2}$ Sefonias Getachew, ${ }^{3}$ \\ Yared Mamushet Yifru, ${ }^{4}$ Muluken Gizaw ${ }^{5}$
}

To cite: Tamrat EG, Gufue ZH, Getachew S, et al. Factors associated with the longerterm unmet supportive care needs of stroke survivors in Ethiopia: a multicentre crosssectional study. BMJ Open 2022;12:e053579. doi:10.1136/ bmjopen-2021-053579

- Prepublication history for this paper is available online. To view these files, please visit the journal online (http://dx.doi. org/10.1136/bmjopen-2021 053579).

Received 19 May 2021 Accepted 07 January 2022

Check for updates

(C) Author(s) (or their employer(s)) 2022. Re-use permitted under CC BY-NC. No commercial re-use. See rights and permissions. Published by BMJ.

For numbered affiliations see end of article.

Correspondence to Edna Gebremichael Tamrat; ednagtamrat@gmail.com

\section{ABSTRACT}

Objectives To assess the magnitude of the longer-term unmet supportive care needs and associated factors among adult stroke survivors.

Design Institutional-based multicentre cross-sectional study.

Setting Between 1 March 2020 and 31 May 2020, in

Addis Ababa, Ethiopia.

Participants Adult stroke survivors (aged $\geq 18$ years, $\mathrm{n}=422$ ), diagnosed with a stroke at least 6 months before the study period and who started regular follow-up at the neurology outpatient clinics in Addis Ababa, Ethiopia.

Main outcome measures Self-reported longer-term supportive care needs.

Results Two hundred and twenty-six (53.6\%) stroke survivors had longer-term unmet supportive care needs, and 196 (46.4\%) survivors had no longer-term unmet supportive care needs. Information need about stroke was reported by $416(98.6 \%)$, and how to travel on public transportation was reported by $340(80.6 \%)$ survivors. These were the most frequently reported unmet needs. Stroke survivors' longer-term unmet supportive care needs were significantly associated with being hypertensive with (adjusted OR (AOR) 4.59; 95\% $\mathrm{Cl} 2.61$ to 8.07), having heart disease with (AOR 1.94; 95\% $\mathrm{Cl} 1.19$ to 3.82), moderate and above level of disability according to the modified Rankin Scale score with (AOR 26.4; 95\% Cl 8.61 to 80.92 ) and unable to use the physiotherapy service with (AOR 2.85; $95 \% \mathrm{Cl}$ of 1.63 to 4.99 ).

Conclusions There are significant longer-term unmet supportive care needs among adult stroke survivors. The factors associated with longer-term unmet supportive care needs were; having comorbidities, moderate and above level of disability according to the modified Rankin Scale score and unable to use the physiotherapy service. The development of appropriate services to address the longerterm unmet supportive care needs of stroke survivors is warranted.

\section{INTRODUCTION}

Globally, stroke is the second-leading cause of death following ischaemic heart disease, being responsible for 8.76 million deaths and taking lives every five seconds. Stroke is the second most common cause of adult disability
Strengths and limitations of this study

- This was the first local study using the standardised instrument for measuring stroke patients' longerterm unmet needs and this can serve as baseline information for further research in Ethiopia and subSaharan Africa.

- The previous studies were mainly focused on the descriptive summary of the unmet needs, but this study tried to identify the factors associated with stroke survivor's longer-term unmet needs.

- Stroke survivors coming to the facility might have more comorbidities and thus report more unmet needs than stroke survivors in the community. Even though the sample size is adequate, generalisation is limited because of the sampling method used.

- Since qualitative data was not collected, a detailed understanding of the longer-term unmet needs among stroke survivors is limited.

$(4.6 \%)$ of the global disability-adjusted lifeyears. ${ }^{1}$ Without significant interventions, the global stroke mortality is estimated to rise to 7.8 million deaths per year by the end of $2030 .^{2}$ The global economic cost of adult stroke is more than 25 billion dollars per year $^{3}$.

Supportive care is defined as, rendering essential services that satisfy stroke patients' physical, psychological, social, informational and spiritual needs over the entire illness trajectory. Supportive care is an essential buffering component of stroke survivors that helps to regain emotional stability, social adjustment, cognitive function, body image, future perspective and physical recovery. ${ }^{4}$

In sub-Saharan Africa (SSA), stroke primarily affects the young and productive segment of the population. ${ }^{5}$ The development of appropriate service provision is limited by the lack of vigorous estimates of longer-term outcomes after stroke and the prevalence of stroke survivors in SSA 
was reported to be $14.6 / 1000$ people. ${ }^{7}$ High burden of uncontrolled vascular risk factors due to low screening and treatment modalities, uncoordinated and fragmentary acute stroke care, and limited rehabilitation services were described as factors associated with poor prognosis after Stroke. ${ }^{57}$ The increase in the magnitude of Stroke, thus calls the urge to identify their unmet needs to accelerate their recovery. ${ }^{8}$

In SSA, the physiotherapists to population ratio range from $0.1 / 100000$ people in Ethiopia to 6.7/100 000 people in South Africa. ${ }^{5}$ There is a high mismatch in the longer-term stroke rehabilitation care need and delivery. Longer-term supportive care service delivery should be patient-oriented and designed compatible with the local situation. ${ }^{9}$ Therefore, assessing the needs of stroke survivors is essential to improve stroke survivors' quality of life. ${ }^{910}$ Even though the unmet need for supportive care for cancer and chronic kidney failure patients is documented, much attention was not given to the supportive care services among stroke survivors. ${ }^{4}$

To the best of our knowledge, we did not get studies conducted in SSA, including in Ethiopia, which determines the longer-term unmet supportive care needs, and associated factors among adult stroke survivors. This study intended to assess the magnitude of the longerterm unmet supportive care needs, and associated factors among adult stroke survivors in Tikur Anbessa Specialised Hospital (TASH) and Saint Paul's Hospital Millennium Medical College (SPHMMC), Addis Ababa, Ethiopia.

\section{METHODS AND MATERIALS}

The study was conducted in TASH and SPHMMC in Addis Ababa, the capital city of Ethiopia. TASH is the first largest government-owned hospital serving as a teaching hospital of Addis Ababa University and a major referral centre from all over the country. TASH provides service to different Neurologic cases at the neurology outpatient department (OPD) twice a week and allocated one additional day to treat stroke survivors in the OPD. SPHMMC is the second-largest hospital in Ethiopia following TASH. It treats neurologic cases 4 days a week in the neurology OPD. The study was conducted from 1 March 2020 to 31 May 2020.

\section{Study design}

An institutional-based multicentre cross-sectional study was conducted.

\section{Participants}

Those adult stroke survivors (aged $\geq 18$ years) who were diagnosed with stroke at least 6 months before the study period and who started follow-up at the neurology OPD of TASH and SPHMMC were considered as the study population. Those stroke survivors who were not able to represent themselves or who did not have anyone to represent them as a caregiver were excluded from the study.
Table 1 Sociodemographic characteristics of adult stroke survivors receiving routine follow-up services Addis Ababa, Ethiopia, 2020 ( $n=422)$

\begin{tabular}{|c|c|c|c|}
\hline Variables & Categories & Frequency & $\%$ \\
\hline \multicolumn{2}{|c|}{ Age, median (25-75th), years } & \multicolumn{2}{|l|}{$54.5(43-62)$} \\
\hline \multirow[t]{6}{*}{ Age (in years) } & $<45$ & 112 & 26.5 \\
\hline & $45-54$ & 99 & 23.4 \\
\hline & $55-64$ & 118 & 28 \\
\hline & $65-74$ & 55 & 13 \\
\hline & $75-84$ & 34 & 8.1 \\
\hline & $>85$ & 4 & 1 \\
\hline \multirow[t]{2}{*}{ Gender } & Male & 243 & 57.6 \\
\hline & Female & 179 & 42.4 \\
\hline \multirow[t]{2}{*}{ Residence } & Urban & 338 & 80.1 \\
\hline & Rural & 84 & 19.9 \\
\hline \multirow[t]{4}{*}{ Region } & Addis Ababa & 307 & 72.7 \\
\hline & Oromia & 77 & 18.3 \\
\hline & Amhara & 19 & 4.5 \\
\hline & Others* & 19 & 4.5 \\
\hline \multirow[t]{4}{*}{ Marital status } & Married & 282 & 66.8 \\
\hline & Never married & 50 & 11.9 \\
\hline & Divorced & 32 & 7.6 \\
\hline & Common law & 58 & 13.7 \\
\hline \multirow[t]{4}{*}{ Religion } & Orthodox & 323 & 76.5 \\
\hline & Protestant & 45 & 10.7 \\
\hline & Catholic & 39 & 9.2 \\
\hline & Muslim & 15 & 3.6 \\
\hline \multirow[t]{6}{*}{ Educational level } & $\begin{array}{l}\text { Unable to read and } \\
\text { write }\end{array}$ & 40 & 9.5 \\
\hline & $\begin{array}{l}\text { Able to read and } \\
\text { write }\end{array}$ & 80 & 18.9 \\
\hline & $\begin{array}{l}\text { Primary school } \\
\text { completed }\end{array}$ & 56 & 13.3 \\
\hline & $\begin{array}{l}\text { Secondary school } \\
\text { completed }\end{array}$ & 101 & 23.9 \\
\hline & Diploma or degree & 107 & 25.4 \\
\hline & Masters and above & 38 & 9 \\
\hline \multirow{7}{*}{$\begin{array}{l}\text { Occupational status } \\
(\mathrm{n}=419)\end{array}$} & Farmer & 59 & 14.1 \\
\hline & $\begin{array}{l}\text { Government } \\
\text { employee }\end{array}$ & 138 & 32.9 \\
\hline & Trader & 53 & 12.7 \\
\hline & NGO & 96 & 22.9 \\
\hline & Unemployed & 39 & 9.3 \\
\hline & Housewife & 15 & 3.6 \\
\hline & Others† & 19 & 4.5 \\
\hline \multirow{5}{*}{$\begin{array}{l}\text { Monthly income } \\
\text { (In US\$) }(n=419)\end{array}$} & $<12$ & 30 & 7.2 \\
\hline & $12-60$ & 120 & 28.6 \\
\hline & $60-120$ & 141 & 33.6 \\
\hline & $120-240$ & 118 & 28.2 \\
\hline & $>240$ & 10 & 2.4 \\
\hline \multirow{2}{*}{$\begin{array}{l}\text { Family size } \\
(n=410)\end{array}$} & $\leq 5$ members & 276 & 67.3 \\
\hline & $>5$ members & 134 & 32.7 \\
\hline
\end{tabular}

*Others: Afar, Southern Nations, nationalities and peoples regional state. †Student and daily labourer.

NGO, non-governmental organisation; USD, United States Dollar. 
Table 2 Clinical characteristics of adult stroke survivors receiving routine follow-up services Addis Ababa, Ethiopia, $2020(n=422)$

\begin{tabular}{|c|c|c|c|}
\hline Patient profile & Categories & Frequency & $\%$ \\
\hline \multirow[t]{3}{*}{ Stroke type } & Ischaemic & 360 & 85.3 \\
\hline & Haemorrhagic & 27 & 6.4 \\
\hline & SAH & 35 & 8.3 \\
\hline \multirow{3}{*}{$\begin{array}{l}\text { Time since last stroke } \\
\text { attack } \\
(n=420)\end{array}$} & 6 months & 50 & 11.9 \\
\hline & $6-12$ months & 107 & 25.5 \\
\hline & $>12$ months & 263 & 62.6 \\
\hline \multirow[t]{2}{*}{ History of recurrence } & No & 230 & 54.5 \\
\hline & Yes & 192 & 45.5 \\
\hline \multirow[t]{2}{*}{ History of hypertension } & Yes & 259 & 61.4 \\
\hline & No & 163 & 38.6 \\
\hline \multirow[t]{2}{*}{ History of diabetes mellitus } & No & 308 & 73 \\
\hline & Yes & 114 & 27 \\
\hline \multirow[t]{2}{*}{ History of heart diseases } & No & 340 & 80.6 \\
\hline & Yes & 82 & 19.4 \\
\hline \multirow[t]{6}{*}{$\begin{array}{l}\text { Level of disability } \\
\text { according to mRS }\end{array}$} & $\begin{array}{l}\text { No symptoms } \\
\text { at all }\end{array}$ & 59 & 14 \\
\hline & $\begin{array}{l}\text { No significant } \\
\text { disability } \\
\text { despite } \\
\text { symptoms }\end{array}$ & 159 & 37.7 \\
\hline & Slight disability & 122 & 28.9 \\
\hline & $\begin{array}{l}\text { Moderate } \\
\text { disability }\end{array}$ & 44 & 10.4 \\
\hline & $\begin{array}{l}\text { Moderately } \\
\text { severe disability }\end{array}$ & 22 & 5.2 \\
\hline & $\begin{array}{l}\text { Severe } \\
\text { disability }\end{array}$ & 16 & 3.8 \\
\hline
\end{tabular}

mRS, modified Rankin Scale; SAH, Subarachnoid hemorrhage.

\section{Sample size determination and sampling technique}

The sample size was determined by applying a single population proportion formula using Epi Info V.7.2.4.0 software, ${ }^{11}$ with the assumptions of a $95 \%$ level of confidence, a $5 \%$ margin of error. Since we could not find any previous studies conducted in Africa to determine the longer-term unmet supportive care needs among adult stroke survivors, the sample size was calculated by taking the largest sample size to detect a statistically significant difference. Accordingly, the percent of stroke survivors who have long-term unmet supportive care needs 50\%, with these assumptions the sample size was 384 , and after adding a $10 \%$ non-response rate the final sample size was 422.

\section{Sampling procedure}

A convenience sampling technique was used to select the study participants, accordingly, all adult stroke survivors who were available at the neurology OPDs of TASH and SPHMMC during the study period who meet the inclusion criteria were included in the study.
Data collection instrument

A pretested structured interviewer-administered questionnaire, which contains the sociodemographic, clinical, neurological factors and the longer-term unmet supportive care needs (LUNs) questions, was used to collect the data. The interviewer-administered questionnaire was prepared in English then translated into the local language (Amharic) and retranslated back to English to maintain its consistency. The level of disability of the stroke survivors was measured by using the modified Rankin Scale (mRS). ${ }^{12}$

The LUNs is a 22-item standardised instrument for measuring stroke patients' longer-term unmet needs. ${ }^{13}$ The 22 variables that were included in the LUNS tool were combined into one by calculating the mean, the mean of these variables was further dichotomised by calculating its population mean as having no unmet need and having an unmet need. If a patient-reported an unmet need that was above the population mean, it is considered as having an unmet need. On the other hand, if a patient reports unmet needs below the mean value it was considered as having no unmet need.

\section{Operational definitions}

Stroke survivor: is a person who has had a stroke attack previously and is not currently receiving acute comma care or receiving an inpatient treatment in a hospital setting. ${ }^{14}$ Longer-term supportive care needs: These include physical relationships, managing money, accessible holidays, pain, driving, memory, information, employment, benefits, daily occupations, bladder control, mood, adaptations outside, diet, home help, moving house, transportation, adaptations inside, falling, mobility, blood pressure. ${ }^{15}$

Needs: Issues and/or actions that are deemed necessary by the survivor to manage his/her well-being and best quality of care. An unmet need: a problem that was not being addressed or one that was being addressed, but insufficiently. Longer-term unmet need: unmet needs that exist at least after 6-month poststroke. ${ }^{15}$ Having longerterm unmet need: having unmet needs that exist at least after 6-month poststroke which are above the calculated mean value.

\section{Data processing, management and analysis}

The collected data was coded and checked for its consistency and completeness up to the end of each data collection period. Before the analysis, the whole data was cleaned and $20 \%$ of the data was double-entered randomly to check for data entry errors and Epi Info V.7.2.4.0 software $^{11}$ was used for data entry. The entered data was exported to STATA V.14.0 for windows. ${ }^{16}$ Descriptive statistics was presented in medians with IQR for numerical variables and categorical variables were presented using frequency and percentages.

The bivariate analysis was done to check the existence of crude association and to select candidate variables, those variables which are clinically important and having $(p<0.25)$ were included in the final model. ${ }^{17}$ 
Table 3 The magnitude of unmet supportive care needs among adult stroke survivors receiving routine follow-up services Addis Ababa, Ethiopia, 2020 ( $n=422)$

\begin{tabular}{|c|c|c|}
\hline \multirow{3}{*}{$\begin{array}{l}\text { Longer-term unmet supportive } \\
\text { care needs } \\
\text { questions }\end{array}$} & \multicolumn{2}{|c|}{ Patient response } \\
\hline & Yes & No \\
\hline & Frequency (\%) & Frequency (\%) \\
\hline Need information about stroke & $416(98.6)$ & $6(1.4)$ \\
\hline $\begin{array}{l}\text { Need blood pressure checkups } \\
\text { frequently }\end{array}$ & $273(64.7)$ & $149(35.3)$ \\
\hline Need help managing pain & $192(45.5)$ & $230(54.5)$ \\
\hline Worsening movement disorders & $180(43)$ & $239(57)$ \\
\hline Afraid of falling again & $297(70.4)$ & 125 (29.6) \\
\hline Need adaptations/aids inside home & $224(53.1)$ & $198(46.9)$ \\
\hline Need adaptations outside home & $212(50.2)$ & $210(49.8)$ \\
\hline Need advice about driving again & $110(26.1)$ & 312 (73.9) \\
\hline $\begin{array}{l}\text { Need advice on travelling on public } \\
\text { transportation }\end{array}$ & $340(80.6)$ & $82(19.4)$ \\
\hline Need help in completing chores & $231(54.7)$ & $191(45.3)$ \\
\hline Need to move to another home & $250(59.2)$ & $172(40.8)$ \\
\hline Need advice about improving diet & $335(79.4)$ & $87(20.6)$ \\
\hline $\begin{array}{l}\text { Need advice about financial } \\
\text { management }\end{array}$ & $244(57.8)$ & $178(42.2)$ \\
\hline Need help to apply for benefits & $302(71.6)$ & $120(28.4)$ \\
\hline $\begin{array}{l}\text { Need advice on employment after } \\
\text { stroke }\end{array}$ & $306(72.5)$ & $116(27.5)$ \\
\hline $\begin{array}{l}\text { Need help to take a bath and cut } \\
\text { my nails }\end{array}$ & $180(42.7)$ & $242(57.3)$ \\
\hline $\begin{array}{l}\text { Need help with my bladder and } \\
\text { bowel activities }\end{array}$ & 142 (33.6) & $280(66.4)$ \\
\hline $\begin{array}{l}\text { Need advice about my physical } \\
\text { relationship }\end{array}$ & 208 (49.3) & $214(50.7)$ \\
\hline $\begin{array}{l}\text { Need help about concentration and } \\
\text { mood }\end{array}$ & $306(72.5)$ & $116(27.5)$ \\
\hline $\begin{array}{l}\text { Need help on how to avoid my } \\
\text { angry or worry }\end{array}$ & 316 (74.9) & $106(25.1)$ \\
\hline $\begin{array}{l}\text { Need advice on how to occupy my } \\
\text { day better }\end{array}$ & $314(74.4)$ & $108(25.6)$ \\
\hline $\begin{array}{l}\text { Need help with catering during } \\
\text { holidays }\end{array}$ & $223(52.8)$ & $199(47.2)$ \\
\hline
\end{tabular}

Confounding was checked, and percentage change in the regression coefficients $(\beta)$ less than $20 \%$ reveals an absence of confounder. Interaction for the main effect model was also be checked and partial likelihood ratio test result with $p>0.05$ and variance inflation factor less than 10 indicating the non-existence of multicollinearity among the independent variables.

The multivariable binary logistic regression model was used to identify the independent factors associated with longer-term unmet supportive care needs. The summary measures of estimated crude and adjusted ORs (AOR) with $95 \%$ CI were presented and $p$ value less than 0.05 was used to declare statistical significance and goodness of fit of the model was assessed by using Hosmer and Lemeshow goodness of fit test. Finally, the results were presented in statements, tables and figure.

\section{Patient and public involvement}

A standard tool was used to collect outcome measures of longer-term unmet supportive care needs (LUNs) questions, was used to collect the data. The intervieweradministered questionnaire was prepared in English then translated into the local language (Amharic) and retranslated back to English to maintain its consistency. The Amharic version was pretested on $10 \%$ of the study participants to check the clarity of the questions and receive feedback from the respondents. Consent was received from each participant before the data collection and the data collectors were trained to provide any information or clarification at any time of the interview. Only participants who wish to continue the study after informed consent were included in the study. The study results are disseminated to the neurology OPD of both hospitals to raise awareness on the unmet needs of the patients so that the health professionals will start to give more emphasis on the most reported unmet needs.

\section{RESULTS}

\section{Sociodemographic characteristics}

A total of 422 adult stroke survivors were included in this study, making the repose rate $100 \%$. Concerning the sex distribution, $243(57.6 \%)$ of the survivors were males. The overall median age of the survivors was 54.5 years with IQR (43-62) years. Three hundred and thirtyeight $(80.1 \%)$ of the survivors were urban residents and $307(72.7 \%)$ were from Addis Ababa. One hundred and seven $(25.4 \%)$ of the survivors have a diploma or degree (table 1).

\section{Clinical characteristics of participants}

Ischaemic stroke was diagnosed among 360 (85.3\%) stroke survivors. Concerning the time from the last stroke attack, $263(62.6 \%)$ stroke survivors had their last stroke attack for more than a year. History of stroke recurrence was reported among 192 (45.5\%) stroke survivors. Hypertension and diabetes mellitus were the most common medical comorbidities reported among 259 (61.4\%) and $114(27 \%)$ stroke survivors, respectively. According to the mRS score, $159(37.7 \%)$ of the survivors had no significant disability despite symptoms, whereas $16(3.8 \%)$ of the stroke survivors had a severe disability (table 2 ).

\section{Physiotherapy service utilisation}

One hundred and fifty-seven (37.2\%) stroke survivors used physiotherapy services, and $265(62.8 \%)$ of the survivors do not use physiotherapy services. Among those who used physiotherapy service, $13(8.3 \%)$ were receiving physiotherapy every day excluding weekends and holidays, meanwhile, $56(35.7 \%)$ of the survivors used 2-3 times per week for $30-45 \mathrm{~min}$. On the other hand, $61(38.8 \%)$ of the survivors used physiotherapy less than two times a week, and 27 $(17.2 \%)$ of the survivors used physiotherapy irregularly. Financial problems, lack of transport service and unsatisfied with the physiotherapy service were the reasons for not using 


\section{MEASURE OF MODIFIED RANKIN SCALE AMONG STROKE PATIENTS WITH UNMET NEED AND WITH OUT UNMET NEED}

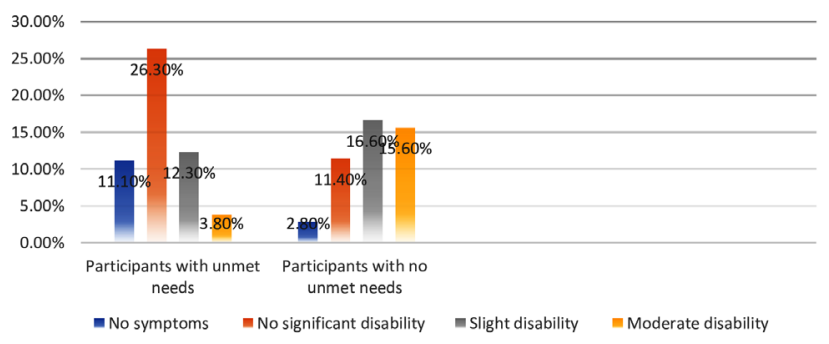

Figure 1 Score of modified Rankin Scale among adult stroke survivors with and without long-term unmet supportive care needs receiving routine follow-up services Addis Ababa, Ethiopia, 2020 ( $n=422)$.

physiotherapy service reported by 100 (38.2\%), 54 (20.6\%) and 108 (41.2\%) survivors, respectively.

\section{The magnitude of unmet supportive care needs}

All stroke survivors reported at least one unmet need, 416 $(98.6 \%)$ survivors stated that they need more information about their stroke, why it happened and how to avoid having another one. The next two common unmet needs were, seeking advice on how to use public transportation reported by, $340(80.6 \%)$ and seeking advice on modifying their diet reported by 335 (79.4\%) (table 3). Two hundred and twenty-sex (53.6\%) stroke survivors had longer-term unmet supportive care needs (LUNs), and 196 (46.4\%) survivors had no longer-term unmet supportive care needs.

\section{Factors associated with longer-term unmet needs}

In the final multivariable binary logistic regression model, after controlling the effect of other confounders, hypertensive stroke survivors are four times more likely to have longerterm unmet supportive care needs than non-hypertensive survivors with (AOR 4.59; 95\% CI 2.61 to 8.07). Similarly, those stroke survivors who have heart disease are two times more likely to have long-term unmet supportive care needs than those who do not have heart disease (AOR 1.94; $95 \%$ CI 1.19 to 3.82$)$.

Those stroke survivors who have a moderate and above level of disability according to the mRS score have a very significant longer-term unmet supportive care needs than those who have no symptoms at all with (AOR 26.4; 95\% CI 8.61 to 80.92 ) figure 1. Stroke survivors who used physiotherapy services are three times less likely to have longer-term unmet supportive care needs than those who do not use physiotherapy services (AOR 2.85; 95\% CI 1.63 to 4.99) (table 4).

\section{DISCUSSION}

\section{Background}

This study assessed the magnitude of the longer-term unmet supportive care needs and its associated factors among adult stroke survivors in TASH and SPHMMC. We found that being hypertensive, having heart disease, moderate and above level of disability according to the mRS score, unable to use the physiotherapy service were the factors associated with the higher experience of the longer-term unmet supportive care needs.

\section{Sociodemographic characteristics}

The median age of the stroke survivors who were included in this study was 54.5 years with an IQR of 43-62 years with males being the majority. This is consistent with several hospital-based studies by which stroke seems to be affecting the younger age groups within this decade. ${ }^{18}$ Even though rural residents were two times more likely to have unmet supportive care needs, we did not get a statistically significant association. This higher unmet need was in line with a study conducted in England by which participants living in less accessible areas to therapy reported more unmet needs. ${ }^{15}$ This might be caused by the lack of health infrastructure and long distance from the rural area to the health facility.

\section{Clinical characteristics}

History of hypertension was reported by $61 \%$ of stroke survivors. Similarly, another study conducted in Addis Ababa Ethiopia mentioned that hypertension occurred in $65 \%$ of the total study participants irrespective of their stroke type. In this study, the history of heart disease was significantly associated with longer-term unmet supportive care needs, this finding goes in line with a study conducted in Europe by which patients who had comorbidities reported more unmet needs than the others. $^{19}$

The level of disability according to the mRS was significantly associated with longer-term unmet needs. This finding was consistent with a study conducted in Germany by which the level of disability of stroke survivors was significantly associated with unmet psychosocial supportive care needs. ${ }^{20}$

Physiotherapy utilisation was reported by $37.2 \%$ of the participants in this study. Similarly, a study which was conducted in West Africa stated that the physiotherapy utilisation of stroke survivors is low. ${ }^{9}$ In this study, not being able to afford the services provided, a long distance from home to the physiotherapy utilisation centres, transportation-related issues, and unsatisfactory services were identified as reasons for not using physiotherapy.

\section{The magnitude of unmet needs}

The magnitude of unmet supportive care needs in this study ranges from $26.1 \%$ (driving needs) to $98.6 \%$ (information needs). Similarly, a study conducted in Germany found that $54 \%$ of survivors reported they need more information about the cause of their stroke and prevention of recurrence. ${ }^{20}$ In our study, $54 \%$ reported needs related to pain management (they have constant pain and nothing seems to ease it). On the other hand, a study conducted in England stated that only $39.5 \%$ of stroke survivors reported unmet needs regarding pain. ${ }^{10}$ This 
Table 4 Factors associated with longer-term unmet supportive care needs among adult stroke survivors, Addis Ababa,

Ethiopia, $2020(n=422)$

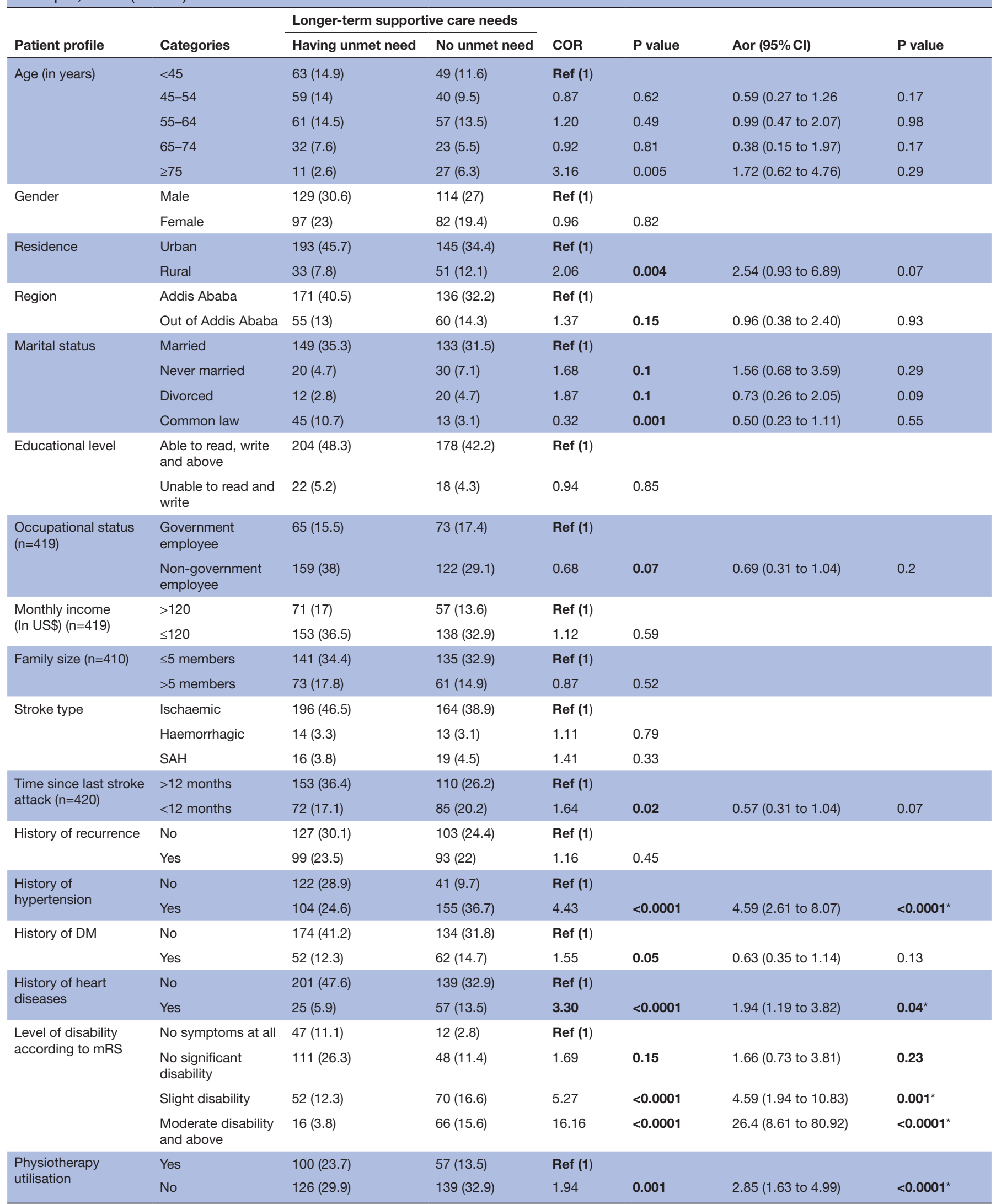

Bold variables were significant at $P p<0.05$,

*Indicates the variables were significant at $\mathrm{p}<0.05$, Ref=reference group (those least to have longer-term unmet supportive care needs were considered as a reference group).

AOR, adjusted OR; COR, crude OR; DM, diabetes mellitus; mRS, modified Rankin Scale; SAH, Subarachnoid hemorrhage. 
difference might be as a result of the medical and rehabilitation system differences of the two countries.

Needing advice on getting back to driving was one of the least reported unmet needs $(26.1 \%)$ while seeking information on how to use public transportation again was one of the highly reported unmet needs (80.6\%). Similar findings were reported in Europe regarding transport and travel concerns. ${ }^{21}$ Adaptations or aids like a stairlift, grab rails inside the home are reported by $53.1 \%$ of the study respondents in this study, whereas adaptations outside the home such as a ramp, rail, or wheelchair were reported by half of the respondents $(50.2 \%)$.

On the other hand, a study conducted in Australia mentioned that mobility aids and home adaptations were provided for $54 \%$ and $31 \%$ of the patient's, respectively, after discharge from the hospital and this facilitated their ability to adapt to ongoing physical disabilities following their stroke. Mobility aids comprised wheelchairs, scooters, walking sticks and frames, which allowed physical functioning as well as independence. ${ }^{22}$

In our study, we found that sexuality needs were reported by $49.3 \%$ of the participants. Intimacy problems were mentioned as one of the most commonly reported emotional problems after stroke according to the study conducted in $\mathrm{USA}^{23}$ and in Europe. ${ }^{10}$ This figure was low and should be understood with attention because talking about sex is taboo or embarrassing in the culture of our setup so patients might not be honest about sexual relationship questions. Moreover, this might eventually make patients distinguish that sexuality is of little significance despite having certain sexual problems.

\section{Limitations of this study}

The study was not without limitations, stroke survivors coming to the facility might have more comorbidities and thus report more unmet needs than stroke survivors in the community. Even though the sample size is adequate, generalisation is limited by the sampling method used. Dichotomising the outcome might have disproportionally affected those who have labelled as having 'no unmet needs'. Since qualitative data were not collected, a detailed understanding of the longer-term unmet needs among stroke survivors is limited. In addition, even though we conducted a pretest to assess the clarity of the LUNS tool a validation study was not conducted as the tool has never been used in Ethiopia. Acknowledging these potential limitations we hope that this finding can serve as baseline information for further research.

\section{CONCLUSIONS}

We have found a significant proportion of adult stroke survivors having a longer-term unmet supportive care need. The factors associated with longer-term unmet supportive care needs were; having comorbidities, moderate and above level of disability according to the mRS score, and unable to use the physiotherapy service.
Author affiliations

${ }^{1}$ Department of Preventive Medicine, Addis Ababa University College of Health Sciences, Addis Ababa, Ethiopia

${ }^{2}$ Department of Public Health, Adigrat University College of Health Sciences, Adrigrat, Tigray, Ethiopia

${ }^{3}$ Department of Preventive Medicine, Addis Ababa University, Addis Ababa, Ethiopia ${ }^{4}$ Department of Neurology, Faculty of Medicine, Addis Ababa University College of Health Sciences, Addis Ababa, Oromia, Ethiopia

${ }^{5}$ Department of Preventive Medicine, School of Public Health, Addis Ababa

University College of Health Sciences, Addis Ababa, Oromia, Ethiopia

Acknowledgements The authors thank all adult stroke survivors who took the time to complete the survey.

Contributors Edna Gebremichael Tamrat was resposible for the project inception, management, statistical analysis and overall write up. Dr Yared: project inception, questionnaire design. Sefonias and Zenawi conducted the statistical analysis and interpreted the findings, Muluken Gizaw: project inception, questionnaire design and supervision. All contributed to this manuscript and approved the final draft.

Funding The authors have not declared a specific grant for this research from any funding agency in the public, commercial or not-for-profit sectors.

Competing interests None declared.

Patient and public involvement Patients and/or the public were involved in the design, or conduct, or reporting, or dissemination plans of this research. Refer to the Methods section for further details.

Patient consent for publication Not applicable.

Ethics approval The study received approval from the institutional review board of the School of Public Health, Addis Ababa University (Ref: SPH/005/2020). Furthermore, the study received an ethical approval from both hospitals where the study was conducted before data collection was started.

Provenance and peer review Not commissioned; externally peer reviewed.

Data availability statement Data are available on reasonable request. The datasets generated and analysed during the current study are available from the corresponding author on a reasonable request.

Open access This is an open access article distributed in accordance with the Creative Commons Attribution Non Commercial (CC BY-NC 4.0) license, which permits others to distribute, remix, adapt, build upon this work non-commercially, and license their derivative works on different terms, provided the original work is properly cited, appropriate credit is given, any changes made indicated, and the use is non-commercial. See: http://creativecommons.org/licenses/by-nc/4.0/.

\section{ORCID iD}

Edna Gebremichael Tamrat http://orcid.org/0000-0002-9748-6021

\section{REFERENCES}

1 GBD. Disease and injury incidence and prevalence Collaborators. global, regional, and national incidence, prevalence, and years lived with disability for 354 diseases and injuries for 195 countries and territories, 1990-2017: a systematic analysis for the global burden of disease study 2017. Lancet 2018;390:1789-858.

2 Strong K, Mathers C, Bonita R. Preventing stroke: saving lives around the world. Lancet Neurol 2007;6:182-7.

3 Association S. Together we can conquer stroke: stroke association strategy 2015 to 2018, 2013: 1-23.

4 Kelley AS, Morrison RS. Palliative care for the seriously ill. N Engl J Med 2015;373:747-55.

5 World Health Organization Regional Office for Africa. Health situation analysis of the African region. Atlas Afr Health Stat2012 https://www. afro.who.int/publications/atlas-african-health-statistics-2012-healthsituation-analysis-african-region

6 Walker R, Whiting D, Unwin N, et al. Stroke incidence in rural and urban Tanzania: a prospective, community-based study. Lancet Neurol 2010;9:786-92.

7 Okoye EC, Awhen PA, Akosile CO, et al. Caregiver-proxy reliability of the Igbo-culture adapted Maleka stroke community reintegration measure: a validation study. Top Stroke Rehabil 2017;24:422-7.

8 Sarfo FS, Akassi J, Kyem G, et al. Long-Term outcomes of stroke in a Ghanaian outpatient clinic. J Stroke Cerebrovasc Dis 2018;27:1090-9. 
9 Sarfo FS, Adamu S, Awuah D, et al. Potential role of telerehabilitation to address barriers to implementation of physical therapy among West African stroke survivors: a cross-sectional survey. J Neurol Sci 2017;381:203-8.

10 Abrahamson V, Wilson PM. How unmet are unmet needs poststroke? A policy analysis of the six-month review. BMC Health Serv Res 2019;19:480-9.

11 Center for disease control and prevention. Epi info, a data base and statistics program for public health professionals. Atlanta, Georgia, USA: Center for disease control and prevention, 2018.

12 Banks JL, Marotta CA. Outcomes validity and reliability of the modified Rankin scale: implications for stroke clinical trials: a literature review and synthesis. Stroke 2007;38:1091-6.

13 LoTS care LUNS study team. Validation of the longer-term unmet needs after stroke (LUNS) monitoring tool: a multicentre study. Clin Rehabil 2013;27:1020-8.

14 Murray CD, Harrison B. The meaning and experience of being a stroke survivor: an interpretative phenomenological analysis. Disabil Rehabil 2004;26:808-16.

15 Hotter B, Padberg I, Liebenau A, et al. Identifying unmet needs in long-term stroke care using in-depth assessment and the PostStroke Checklist - The Managing Aftercare for Stroke (MAS-I) study. Eur Stroke J 2018;3:237-45.
16 StataCorp. Stata statistical software: release 14. College Station, Texas, USA: StataCorp LLC, 2017.

17 David WH, Stanley L. Applied logistic regression. 2nd edn. Massachusetts, USA: Wiley series in probability and statistics, 2000: 95.

18 Deresse B, Shaweno D. Epidemiology and in-hospital outcome of stroke in South Ethiopia. J Neurol Sci 2015;355:138-42.

19 Benjamin EJ, Virani SS, Callaway CW, et al. Heart disease and stroke Statistics -2018 update: a report from the American heart association. Circulation 2018;137.

20 Lehnerer S, Hotter B, Padberg I, et al. Social work support and unmet social needs in life after stroke: a cross-sectional exploratory study. BMC Neurol 2019;19:1-10.

21 Chen T, Zhang B, Deng Y, et al. Long-Term unmet needs after stroke: systematic review of evidence from survey studies. BMJ Open 2019;9:e028137.

22 Murgo M, Cavanagh K, Latham S. Health related quality of life and support needs for sub-arachnoid haemorrhage survivors in New South Wales Australia. Aust Crit Care 2016;29:146-50.

23 McCurley JL, Funes CJ, Zale EL, et al. Preventing chronic emotional distress in stroke survivors and their informal caregivers. Neurocrit Care 2019;30:581-9. 